\title{
PUESTAS EN ESCENA DE OBRAS DE DRAMATURGAS \\ EN LA CARTELERA DE ABC DE MADRID (1980-1984) ${ }^{1}$
}

\author{
STAGE PRODUCTION OF WOMEN PLAYWRIGHTS \\ IN THE BILLBOARD OF ABC DE MADRID (1980-1984)
}

\author{
Annalisa Domenica BONACCORSI \\ Grupo de Investigación del SELITEN@T \\ annalisa_bonaccorsi@yahoo.it
}

Resumen: El objetivo de este artículo es analizar las piezas teatrales de autoría femenina representadas en Madrid en los años 1980-1984, sobre las que aparecieron referencias en el diario $A B C$ de Madrid durante el quinquenio. Trataremos de examinar sus vidas y sus trabajos, con una atención especial al difícil contexto cultural y social en el que tenían que vivir y trabajar las dramaturgas:

Palabras clave: Teatro. Dramaturgas. ABC de Madrid. Años 1980-1984.

Abstract: The aim of this article is to analyze the women playwrights' plays that were represented in the years 1980-1984 in Madrid and that appeared in the Spanish daily ABC de Madrid in the same years. We will examine their lives and works, trying to investigate into the difficult cultural and social context in which they had to live and work.

Key Words: Theatre. Women Playwrights. ABC de Madrid. Years 1980-1984.

1 Este trabajo se inserta dentro d elas actividades del Centro de Investigación de Semiótica Literaria, Teatral y Nuevas Tecnologías, dirigido por el Dr. José Romera Castillo, cuyas actividades pueden verse en http:// www.uned.es/centro-investigacion-SELITEN@T. 


\section{INTRODUCCIÓN}

No podemos detenernos en el estudio de la cartelera teatral madrileña en la década de los ochenta, ni en la presencia de las dramaturgas en los escenarios, en sus contextos históricos, artísticos y teatrales, debido a los condicionantes de espacio que la revista exige. Como es bien sabido, históricamente, la literatura y el teatro han representado siempre y principalmente el mundo masculino, su punto de vista y su ideología. Las mujeres vivían relegadas en sus hogares, atrapadas a sus funciones de madre y esposa, mientras los hombres, como escribe Patricia O'Connor:

[...] a lo largo de los siglos, han hecho suyas las calles, los lugares de comercio, los edificios públicos [....]. Han ganado sueldos, han merecido respeto, han adquirido poder, y han legado su propiedad a sus hijos (preferentemente varones) (O'Connor, 1988: 10).

En general, para la mujer ha sido quizás más fácil expresarse a través de la poesía y la narrativa, género considerado tradicionalmente más compatible con las características femeninas. Como señala la mencionada crítica:

En cuanto a la tradición literaria, existe la creencia ampliamente difundida de que la narración, menos estructurada, menos limitada y más espontánea que el drama y con una obvia relación con la tradición oral, es un género compatible con los talentos "femeninos". Por el contrario el teatro, al requerir disciplina, síntesis, brillantez verbal, conocimientos sociales, y acción, se ha considerado un género apropiado a los talentos y experiencias masculinos (O'Connor, 1988: 13).

Pero la situación, tras el franquismo, empieza a cambiar un tanto, aunque lentamente. Así, por ejemplo, en 1987, nacía la Asociación de Dramaturgas Españolas, integrándose en 1990 en la Asociación de Autores de Teatro. En los años ochenta las mujeres se empeñan en hallar un espacio para su discurso, y la nueva sociedad española, democrática, propicia la formación de entidades que les facilitan las ayudas que necesitan. Este es el caso del Instituto de la Mujer, que nace en 1983 como organismo autónomo adscrito al Ministerio de Cultura ${ }^{2}$, con el intento de promover y fomentar las

2 Cabe recordar que el Instituto estuvo adscrito al Ministerio de Cultura hasta 1988, año en el que pasó a formar parte del Ministerio de Asuntos Sociales, que se unió al de Trabajo posteriormente. A partir de 2004, se vinculó a este, a través de la Secretaría General de Políticas de Igualdad. 
condiciones que posibiliten la igualdad social y la participación de las mujeres en la vida política, cultural, económica y social del país.

Las condiciones sociales empiezan pues a ser favorables para las mujeres, aunque las dificultades para llegar a los escenarios aún existen. En cambio, se llevan a cabo ediciones de textos, y las escritoras empiezan a aparecer públicamente en coloquios y entrevistas, gracias a los cuales se dan a conocer. Estas entrevistas, afortunadamente, fueron transcritas en las publicaciones teatrales de la época, así que han podido llegar hasta nosotros. Entre ellas, recordamos Primer Acto, Estreno y El Público, que actuaron de trampolín para muchas de las dramaturgas de finales de siglo.

El año 1984 es importante para las dramaturgas españolas: la revista Estreno, guiada por Patricia W. O'Connor, les dedica monográficamente el número de otoño. Las páginas de la revista se llenaron de escritoras muy diferentes entre ellas, pero todas agrupadas por el deseo de ser escuchadas. Otra etapa básica para las autoras es la publicación, en 1988, de Dramaturgas españolas de hoy, por Patricia O'Connor, una antología de textos breves de autoras contemporáneas, que incluye en sus páginas finales un índice biobibliográfico de las dramaturgas españolas del siglo XX, con noventa y cinco autoras. A partir de este momento, algunas historias de la literatura dramática empiezan a incluir los nombres de las autoras en sus páginas.

Según Patricia O'Connor (1988), las dramaturgas españolas viven en la segunda mitad del siglo XX cuatro etapas diferentes, que llevan a estas mujeres a una revisión, término con el cual la autora entiende "ver con nuevos ojos". En la primera etapa, las dramaturgas usan un lenguaje y temas propiamente femeninos, en los que prevalece la idealización de la mujer virtuosa y sumisa. En los años sesenta y setenta, en cambio, las autoras empiezan a expresar sus propias ideas, aunque con límites; mientras que, en la tercera, que corresponde más o menos a los años setenta y ochenta, tienden a imitar a los dramaturgos masculinos en sus temas y en su lenguaje. En el último período, finalmente, las mujeres empiezan a expresarse libremente, volviendo a temas femeninos también, pero desde una perspectiva más libre y auténtica.

Lo que vino después, de un lado, ha sido examinado, entre otras aportaciones, en un proyecto europeo, DRAMATURGAE, cuyo fin no era otro que estudiar el teatro actual, escrito por mujeres y en español. En efecto, por iniciativa del profesor Romera Castillo, tres universidades europeas se pusieron a la tarea, a través de tres encuentros internacionales: el primero, en la UNED, sobre Dramaturgias femeninas en la segunda mitad del siglo XX: espacio y tiempo (Romera Castillo, ed., 2005); el segundo, en la Universidad de ToulouseLe Mirail (Francia), sobre Transgression et folie dans les dramaturgies féminines hispaniques contemporaines (Roswita / Garnier, eds., 2007) y el tercero, en la Justus-Liebig Universität Giessen (Alemania), sobre Dramaturgias femeninas en el teatro español contemporáneo: entre pasado y presente (Floeck et alii, eds., 2008). 
Por otro lado, apuntaremos que, entre la bibliografía referida al asunto, remitimos solamente a algunos trabajos, realizados en el Centro de Investigación de Semiótica Literaria, Teatral y Nuevas Tecnologías (cuyas actividades pueden verse en http://www. uned.es/centro-investigacion-SELITEN@T), bajo la dirección del profesor José Romera Castillo, quien a su vez ha tratado el tema en varios trabajos $(2010,2011,2014)$; además de los artículos de dos integrantes del grupo de investigación: los de Valeria Lo Porto (2012) y Anita Viola (2012b), sobre la cartelera en ABC de Madrid, en los años 1990 y 2000, respectivamente ${ }^{3}$.

Añadiremos que en el Centro de investigación, bajo la dirección del Dr. Romera Castillo, se han defendido tres tesis de doctorado: la de Valeria Lo Porto (2013). Cartelera teatral en ABC de Madrid (1990-1994) (inédita, aunque puede leerse en http://www.uned.es/centroinvestigacion-SELITEN@T/pdf/ValeriaLoPorto.pdf); la de AnitaViola (2012a).Cartelera teatral en $A B C$ de Madrid (2000-2004) (inédita hasta el momento en formato impreso, aunque puede leerse en la web del Centro: http://www.uned.es/centro-investigacion-SELITEN@T/ pdf/AnitaViola.pdf-); y la nuestra, Annalisa Bonaccorsi (2015), Cartelera teatral en " $A B C$ " de Madrid (1980-1984), también está inédita hasta el momento en formato impreso, aunque puede leerse en la web del Centro: http://www2.uned.es/centro-investigacion-SELITEN@T/ pdf/Tesis_Cartelera_teatral_ABC_Madrid_1980-1984.pdf. En ellas -especialmente en la que esto suscribe- se podrá encontrar una contextualización, en los diferentes períodos, de las dramaturgias femeninas en los escenarios madrileños.

\section{DRAMATURGAS EN LA CARTELERA TEATRAL MADRILEÑA (1980-1984)}

De las 28 dramaturgas que pusieron en escena sus obras en el período analizado, y recogidas en nuestro estudio, anteriormente citado (Bonaccorsi, 2015), nos referiremos a continuación a las siete dramaturgas siguientes (que enumeramos por orden alfabético): Antonia Bueno Mingallón, Ana Diosdado, Isabel Hidalgo Muñoz, María Teresa León, Roma Mahieu, Lourdes Ortiz y Marta Schinca. Todas estrenaron o representaron al menos una obra en el quinquenio 1980-1984. Además de dar unos breves apuntes biográficos, nos fijaremos fundamentalmente en la pieza teatral llevada a los escenarios en el quinquenio analizado, consignadas en el periódico madrileño.

3 En el n. ${ }^{\circ} 21$ (2012) de la revista Signa, dirigida por el profesor Romera, aparecen dos secciones monográficas: Sobre lo grotesco en autoras teatrales de los siglos XX y XXI, coordinada por Raquel García-Pascual (11-197) y Sobre teatro breve de hoy y obras de dramaturgas en la cartelera madrileña (1990 y 2000), coordinada por José Romera Castillo (199-415), que también pueden leerse en http://bib.cervantesvirtual.com/servlet/ SirveObras/06925171155959240910046/index.htm [03/04/2016]. 


\subsection{ANTONIA BUENO MINGALLÓN}

\subsubsection{Apuntes biográficos}

Nacida en 1945, Antonia Bueno Mingallón es una dramaturga, directora y actriz teatral española. En 1979 crea en Madrid la compañía teatral Teatro Guirigai. Durante más de 20 años, coodirige la gestión artística en diecisiete espectáculos de la compañía. Como actriz, participa en todos los espectáculos de la compañía. Es autora de numerosos textos, guiones de espectáculos de calle, traducciones y versiones de teatro musical, la mayor parte de éstos editados. Dirige un abundante número de piezas, entre los cuales recordamos La Parranda, de Eduardo Blanco-Amor, representado en Rusia, Brasil y Estados Unidos, entre los primeros, y Jornada de reflexión, Métele caña, España, de Fernando Bellón, estrenado en Madrid, entre los últimos.

En el año 2000 crea su propia compañía de teatro, con la que produce y dirige su obra Sancha, reina de la Hispania, que recibe el Premio Especial de Jurados en el IV Certamen Nacional de Directoras de Escena 2001, y que constituye la primera parte de la Trilogia de mujeres medievales, publicada por la Revista ADE-Teatro en 2003 y por la Asociación de Estudios Onienses en 2007.

Desde hace cinco años reside en Valencia. Es Presidenta de DONES en ART, Dones de I'Escena Valenciana Associades, que en 2009 ha celebrado su IV Aniversario en torno a un "Ciclo de dramaturgas republicanas", creado y coordinado por Antonia Bueno. En 2009 la autora ha recibido también el XVI Premio ASSITEJ-España de Teatro para la Infancia y la Juventud, por su obra Ópera de los residuos. (http://www.redescena.net/compania/29484/ antonia-bueno-mingallon/) [03/04/2016].

\subsection{2. Ágape}

En su estudio “La Edad Media a través de la mirada femenina en la trilogía de Antonia Bueno" (Romera, ed., 2006: 625-635), M. ${ }^{a}$ Elisa González Herrero, describe a Antonia Bueno Mingallón como una de las autoras más interesantes del panorama general de la escena española contemporánea, con una línea de creación basada principalmente en el tema de la mujer, sus angustias y problemas pasados y actuales. Esta dramaturga ha sabido elaborar todo un mundo creativo que mezcla realidad, poesía, historia y actualidad (Piñeiro Barderas, 2012: 100).

Estrenada en noviembre de 1983, en el Teatro Municipal de Getafe, y en Madrid el 4 de febrero de 1983, a las 22:30 h., en la Sala Gayo Vallecano, Ágape es una creación del grupo Guirigay sobre una idea de Antonia Bueno y Agustín Iglesias, quien dirigió el espectáculo. La obra sigue estando inédita hasta el momento. Los actores que intervinieron fueron los 
mismos: Antonia Bueno y Agustín Iglesias, junto a Miguel Gredilla y Maite Martín Moro. El espectáculo fue representado 12 veces en el año 1983, desde el 4 hasta el 27 de febrero, en la Sala el Gayo Vallecano y dos veces en el 1984, el 20 y el 21 de septiembre, con ocasión de la Muestra de Nuevo Teatro Joven Madrileño-Semana de la Juventud, esta vez en la Sala Olimpia, perteneciente al Centro Dramático Nacional.

El espectáculo presenta como temas fundamentales el amor, la gastronomía y los sueños. La pareja central, que celebra su quinto aniversario, se encuentra delante de una mesa llena de viandas. A través de una serie de metáforas y de juegos de lenguaje que tienen siempre como base el mundo culinario, los personajes llegan a la coprofagia. Ágape, de hecho, trata de representar la crisis generacional de los treintañeros a través de la gula. Eduardo Haro Tecglen, en su artículo publicado en El País, el 6 de febrero de 1983, escribía:

Así animados, interferidos por personajes quizá imaginarios, quizá representaciones de recuerdos, quizá pesadillas de digestión -los quizá sustituyen aquí la certidumbre de lo que puedan ser los personajes enmascarados que aparecen y desaparecen por donde pueden-, llegan a la culminación del espectáculo: la coprofagia. Realizan allí mismo, ante el público, su labor de exoneración corporal, la sirven en la mesa [...] y la degustan. Con buen ánimo se podrían sacar teorías acerca de la autodestrucción, de la degeneración, de una cierta forma de terror cotidiano: pero sin la seguridad de que sea eso lo que han pretendido quienes tuvieron una idea (Haro, 1983: ed. el.).

\subsection{ANA DIOSDADO}

\subsubsection{Apuntes biográficos}

Conocida como una de las autoras y dramaturgas más importantes de la literatura española contemporánea, Ana Isabel Álvarez Diosdado Gisbert nace el 21 de mayo de 1938 en Buenos Aires, donde sus padres, los actores Enrique Diosdado e Isabel Gisbert, permanecían exiliados tras el estallido de la Guerra Civil en España. Desde niña comienza su relación con el teatro, actuando, con solo 5 años de edad, en Mariana Pineda con la compañía de Margarita Xirgu, su madrina de bautismo. En 1950 llega a España, estudia en el Liceo Francés y actúa en la compañía del padre. Estudia Filosofía y Letras en la Universidad Complutense de Madrid, pero lo abandona los estudios antes de obtener la licenciatura para escribir relatos y artículos. 
En 1969 es finalista del premio Planeta con su novela Campanas que aturden, texto que no se llega a publicar. En 1970 escribe y estrena su primera obra teatral, Olvida los tambores, uno de sus mayores éxitos en los escenarios, y obtiene el Premio Maite y el Foro Teatral. También se dedica a escribir guiones de televisión, entre otros Anillos de oro, en 1983, junto a Imanol Arias, que se convierte en una de las series de mayor éxito en la historia de la televisión española. Anillos de oro recibe varios premios en España y en Hispanoamérica, y Segunda enseñanza, otra serie televisiva, es seleccionada en Estados Unidos como una de las diez mejores series extranjeras del año. Ana Diosdado obtiene columna propia en Diario 16 y en el $A B C$.

En 1999 se separa del actor Carlos Larrañaga y en 2001 se convierte en presidenta de la SGAE. En 2013 recibe el Premio Max de Teatro a su carrera. En el mismo año es diagnosticada de leucemia crónica, y en agosto del año siguiente sufre un derrame cerebral. El 5 de octubre de 2015 fallece en la sede de la SGAE, tras un desvanecimiento durante una reunión de trabajo de la sociedad (http://escritoras.com/escritoras/AnaDiosdado) [03/04/2016].

\subsubsection{Olvida los tambores}

Patricia O' Connor define en uno de sus estudios a Ana Diosdado como una de las dramaturgas más conocidas y de mayor éxito de los años ochenta, y añade:

Pionera en varios sentidos, Diosdado rompió moldes y sirvió de modelo para otras mujeres que querían escribir para teatro. En la época dramática, sin embargo, ha dejado el liderazgo en este sentido. [...] Diosdado no ha progresado en la época democrática en cuanto a la presentación de la mujer (O'Connor, 1988: 40).

Sin embargo, tal y como afirma Virtudes Serrano en "Memoria y autobiografía en la dramaturgia femenina actual" (Romera, ed., 2003: 47-62), Ana Diosdado, desde su primera obra, Olvida los tambores, en 1970, ha tenido el mérito de presentar y mantener visible la figura de la mujer en el teatro español, describiendo al mismo tiempo la vida de los jóvenes españoles desde los años sesenta hasta los primeros años de la democracia en Cuplé (1986) (Piñeiro Barderas, 2012: 105).

Olvida los tambores ${ }^{4}$ es la primera obra de teatro de Ana Diosdado. Se estrenó el día 28 de junio de 1970 en el Teatro Principal de Zamora, y en Madrid el 4 de septiembre del mismo año, en el Teatro Valle-Inclán. La función se convirtió de inmediato en un gran éxito

4 Para las referencias bibliográficas de las obras dramáticas analizadas en este texto, remitimos a la bibliografía que se encuentra al final del artículo. 
y en un referente para los espectáculos teatrales de principios de los setenta. Dirigida por Ramón Ballesteros, su reparto original estaba compuesto por María José Alfonso, Juan Diego, Mercedes Sampietro, Jaime Blanch, Emilio Gutiérrez Caba y Pastor Serrador. En 1975, cinco años más tarde, fue adaptada al cine, bajo la dirección de Rafael Gil.

En el quinquenio analizado, se representó dos veces en Madrid, el 13 y el 14 de junio de 1981, a las 19:30 h., en la sede de la Agrupación Madrileña de Arte, situada en el Paseo de las Delicias, por la compañía teatral Tiempo Nuevo.

A continuación, citamos a Víctor Conde, que en 2007 dirigió la obra que volvió a ser representada en el teatro La Latina de Madrid, porque consideramos interesante su opinión y su descripción de la dramaturga:

A principios de 2007, mi amigo Antonio Albella buscaba una obra de teatro en la que poder trabajar juntos. [...] Olvida los tambores merecía una revisión y ser presentada a nuevas generaciones de espectadores. Alberto Blasco se entusiasmó enseguida cuando pusimos el proyecto sobre su mesa y tardó solo un día en tomar la decisión de asumir la producción de la obra. Pocos meses más tarde ya estábamos ensayando. El proyecto, sin embargo, nunca podría haber visto la luz sin el entusiasmo, complicidad, talento y apoyo de su autora, Ana Diosdado, sin duda la dramaturga [...] más importante de este país. Ana se implicó desde el primer momento. Asistió a las lecturas, a varios ensayos, y siempre respetuosa nos hacía ver un poco más allá de nuestro trabajo, guiándonos de manera sabia hacia nuestro objetivo. La aportación de Ana Diosdado, el hecho de haber trabajado, aprendido y compartido la puesta en escena de la que fue su primera obra casi cuarenta años atrás, es sin lugar a dudas el regalo más preciado que nos llevamos todos los que participamos en la producción de Olvida los tambores (Conde, 2007: ed. el. ).

Tony y Alicia son un joven matrimonio ajeno a convencionalismos, que vive su amor de manera libre y sin hacer concesiones a la rutina y a lo establecido. Tony forma junto a su amigo Pepe un grupo musical que lucha por encontrar su sitio en el mercado. El día del aniversario de Alicia y Tony se celebra una cena de trabajo de la que depende el futuro laboral del grupo musical de Tony y Pepe con Nacho, un importante productor discográfico interesado en el grupo y que parece va a dar a los dos amigos la oportunidad que buscaban. Ese mismo día llega Pili, la hermana de Alicia, huyendo de su matrimonio aburrido y rutinario con Lorenzo, un joven arquitecto conservador, que también acude al apartamento de Alicia para intentar convencer a su mujer que vuelva con él. La cena juntará pues todos los personajes, que a través de Nacho destaparán sus verdaderos 
sentimientos, miedos y secretos. Después de esta noche, los seis personajes deberán afrontar sus vidas y asumir las cargas de la madurez.

Olvida los tambores fue un testimonio de una parte de los jóvenes españoles de los años setenta, de sus inquietudes y expectativas, pero la obra mantiene buena parte de su interés a pesar de los años transcurridos porque, en definitiva, trata sobre problemas humanos atemporales, como las frustraciones de la juventud, los conflictos generacionales y el difícil paso a la madurez.

\subsection{ISABEL HIDALGO MUÑOZ}

\subsubsection{Apuntes biográficos}

Desafortunadamente, no se conocen muchos detalles sobre la vida de Isabel Hidalgo. Solo en la obra Autoras en la historia del teatro español (1500-2000), dirigida por Antonio Hormigón (2000), hemos podido encontrar algunas informaciones sobre esta dramaturga, aunque muy pocas e incompletas. Estudia en el Real Conservatorio de Madrid, y empieza su carrera profesional en 1965 como actriz, interviniendo en numerosas obras de teatro, películas y programas de televisión. En 1974 traduce y adapta ¿Quién mató a Papá Noel?, obra inglesa inédita de Terence Feely, que se estrenó en Madrid, el 6 de junio de 1974, en el Teatro Alcázar. Además de Las desempleadas, la comedia que vamos a analizar, es autora de Todas hijas de su madre, un drama en dos actos estrenado el 6 de septiembre de 1989 en el Teatro Reina Victoria de Madrid, y publicado al año siguiente, y El casto fornicador, que no fue estrenada (Hormigón, 2000: 450-453).

\subsubsection{Las desempleadas}

El primer trabajo de Isabel Hidalgo como dramaturga fue Las desempleadas, que se estrenó en el Teatro de la Comedia de Madrid, el 12 de agosto de 1980 a las 23:00 h. Bajo la dirección de Víctor Andrés Catena, actuaron en la comedia Eva León, José Luis Lespe, Maribel Hidalgo, Sergio Mendizábal, Cayetano Mendoza y Herlinda Feijoo. Durante el año 1980, este espectáculo se representó 61 veces en Madrid. El año siguiente, el espectáculo volvió a representarse 110 veces. Esta vez, se escenificó en el teatro Alcázar, y siempre, bajo la dirección de Víctor Andrés Catena, actuaron Maribel Hidalgo, Carlos Mendy, Herlinda Feijoo, Charo Tijero, Sergio Mendizábal, Cayetano Mendoza y Miguel Velasco.

Cuatro mujeres, Epifanía, Marilina, Sara y Silvia, viven juntas en una casa de alquiler. La única que trabaja, Sara, pierde su empleo. Las chicas quedan pues sin dinero, y entonces Sara convence a las otras a abrir un prostíbulo en su casa. A partir de este momento, 
suceden una numerosa serie de hechos: llega un detective de Barcelona convencido de que Sara es una estafadora (la empresa estafada es, por otra parte, la del padre de Silvia); Silvia se enamora de Sara, que en realidad es un hombre. Al final, Sara va a la cárcel, pero el padre de Silvia promete ayudarle.

No es fácil definir esta obra. Muchos críticos han juzgado negativamente la comedia a causa de los numerosos hechos que acaecen desde que las cuatro amigas deciden abrir el prostíbulo:

[...] lo que parecía una comedia discreta se va convirtiendo en una sucesión de hechos inconexos, con entradas y salidas de personajes de lo más variopinto. [...] Llega un momento en el que las situaciones se suceden atropelladamente sin demasiadas explicaciones (Hormigón, 2000: 450-451).

El 21 agosto de 1980 ABC publica un artículo de Lorenzo López Sancho sobre esta pieza. El juicio no es completamente negativo, aun con reservas:

[...] Como hay escenas graciosas, el público ríe con frecuencia. Lo increíble de la historia se admite con buena voluntad y aunque no pueda decirse que estamos ante una pieza cómica lograda, pese a la modestia de sus pretensiones, es justo decirquelsabel-Maribel Hidalgo, ha acopiado materiales y situaciones con las que barajando algo más expertamente podría haberse sacado un vodevil de verdad. Si insiste, probablemente lo conseguirá en otra ocasión (López Sancho, 1980a: 39).

\subsection{MARÍA TERESA LEÓN}

\subsubsection{Apuntes biográficos}

María Teresa León Goyri nace en Logroño el 31 de octubre de 1903, hija del coronel del ejército Ángel León y de Oliva Goyri. Se educa en un ambiente culto, ilustrado. Estudia en la Institución Libre de Enseñanza y se licencia en Filosofía y Letras. En 1920, a los diecisiete años de edad, contrae matrimonio con Gonzalo de Sebastián Alfaro, con quien tiene dos hijos, Gonzalo y Enrique. Escribe artículos para el Diario de Burgos, bajo el seudónimo de la heroína de D'annunzio, Isabel Inghirami, y posteriormente con su propio nombre. En 1928 realiza un viaje a Argentina, y al año siguiente publica sus primeras obras, Cuentos para soñar y La bella del mal amor. El mismo año conoce a Rafael Alberti, que sería su compañero de por vida; se separa entonces de su marido y los dos 
se escapan a Mallorca, teniendo que dejar atrás a sus hijos, dado que por entonces la custodia recaía indefectiblemente en el esposo. En 1932 se casan por lo civil. Los dos comienzan a viajar por Berlín, la Unión Soviética, Dinamarca, Noruega, Bélgica y Holanda. En 1934, al estallar la Revolución de Asturias, viajan a los Estados Unidos, para recaudar fondos para los obreros damnificados. Cuando en 1936 empieza la Guerra Civil Española, ellos están en Ibiza, donde tienen que esconderse. Una vez instalados en Madrid, María Teresa pasa a ejercer el cargo de secretaria de la Alianza de Escritores Antifascistas, y funda la revista El Mono Azul. Durante la guerra, su trabajo se centra en el teatro, siendo Subdirectora del Consejo Central del Teatro, promoviendo distintas iniciativas en este campo, y es responsable de "El Teatro de Arte y Propaganda" y, posteriormente, de "Las Guerrillas del Teatro" en el Ejército del Centro (Bando republicano). La derrota republicana obliga a la pareja a un exilio de 40 años que les lleva a Francia, Argentina e Italia. En París viven hasta finales de 1940, trabajando como traductores de la radio francesa ParisMondial y como locutores para las emisiones de América Latina. Viven durante 23 años en Argentina, naciendo allí su hija Aitana. Es en Argentina donde María Teresa recupera a uno de sus hijos, Gonzalo, el mayor, que va en su busca a Buenos Aires, después de 20 años separados. En 1963 la pareja se traslada a vivir a Roma.

Con la llegada de la democracia, Rafael Alberti y María Teresa León vuelven a España el 27 de abril de 1977, pero ella no disfruta mucho de la nueva etapa española. Aquejada del mal de Alzheimer, pierde la memoria y cada vez más enferma, no reconoce a sus amigos. Es ingresada en un sanatorio de las cercanías de Madrid, donde fallece el 13 de diciembre de 1988 (http://escritoras.com/escritoras/Maria-Teresa-Leon) [03/04/2016].

\subsubsection{Juan bobo}

Juan bobo fue representado 7 veces en el quinquenio analizado, del 5 al 26 de marzo de 1983, en la Sala 2 del Centro Cultural de la Villa de Madrid, a las 16:30 h., por el grupo teatral Teloncillo.

Juan bobo es un cuento de María Teresa León que reelabora un personaje de la tradición folklórica, el del pícaro que utiliza su falsa ignorancia para hacer dinero con engaño. A esta tradición la autora añade su sentido del humor y su notable capacidad creadora:

Sobre unos elementos narrativos muy sancionados por una tradición folklórica, María Teresa León desarrolla un inteligente sentido del humor actualizando un viejo tema que ya había sido utilizado por Cervantes en su entremés La cueva de Salamanca (Torres Nebrera, 1984: 368). 
El cuento está incluido en Rosa-Fría, patinadora en la luna, una colección de nueve fábulas de tintes surrealistas ilustradas por Rafael Alberti y publicada en 1934. El título hace referencia al primero de los cuentos, que a su vez toma el personaje de un poema de Rafael Alberti. Considerado uno de los libros de cuentos más original de la narrativa contemporánea, por su inteligente mezcla de tradición y vanguardia, contiene cuentos tradicionales en nueva escritura, como el mismo Juan bobo, junto a El gallo Perico y El lobito de Sierra Morena, además de otros cuentos más vanguardistas y surrealistas como El ladrón de islas.

La compañía teatral Teloncillo nace en el año 1968. En 1983, Jesús Martín “El primo”y Manolo Pérez crean un espectáculo para niños basado en el cuento de María Teresa León y en el personaje popular "el tonto del pueblo", como escribe el mismo Manolo Pérez:

De la mano de Jesús Martín (El primo) y Manolo Pérez, levantamos un espectáculo alegre, festivo, musical... Juan bobo...basado en una versión del "tonto de pueblo" que circulaba por la Cerdanya catalana - mezclada con un maravilloso texto de Maria Teresa León- lugar en el que Jesús Martín se encontraba dando clases...increíble, tres meses de trabajo, estreno en Valladolid y Salamanca, en las fiestas...más de 300 actuaciones en tres años!!! Escenografía basada en la comedia del arte, máscaras... a cargo de Luis Navarro (arquitecto y urbanista) colaborador habitual de la compañía desde sus comienzos. Un elenco relativamente amplio: cinco personas que nos doblábamos técnica e interpretativamente, música en directo, juegos, enredos... un éxito enorme con el que llegamos a hacer una gira de más de un mes en Barcelona, en el circuito de La Caixa, con actuaciones en Badalona a teatro lleno de chavales, o en Sant Adriá del Bessós, en el conflictivo barrio de La Mina, entre otros lugares [...] (Pérez, 2007: ed. el.).

\subsection{ROMA MAHIEU}

\subsubsection{Apuntes biográficos}

Roma Mahieu (Polonia, 1937), a los 10 años emigra con su familia a Argentina, donde estudia danza, pintura, teatro y cerámica. Empieza su carrera como actriz en grupos independientes en Argentina y Alemania, realiza varios trabajos como periodista, dirige espectáculos infantiles, participa en encuentros de dramaturgos y forma parte de jurados en festivales. Escribe principalmente teatro, aunque se dedica también a otros géneros, como guiones televisivos (Historia de amor y de muerte), 
piezas radiofónicas, cuentos y novelas (Diario íntimo de Odolinda Correa, Sagrario y Lo que me molesta es salir a la calle y juntar sus pedazos). Casada con el escritor y crítico José Agustín Mahieu, se confirma como dramaturga en 1976, cuando estrena Juegos a la hora de la siesta. Su pieza teatral es muy bien recibida por público y crítica, y obtiene diversos premios en Argentina y Brasil, como el premio Molière, Talía Argentores y el Premio Nacional de Teatro del Ministerio de Cultura de Brasil. En 1978 es prohibida por la dictadura militar argentina por "su contenido manifiesto de postulados disociantes y la descripción de técnicas propias de la subversión" (Gorlero, 2006:1). Lo mismo sucede con su obra María la Muerte, del mismo año.

Se exilia en España donde dirige el Festival Hispanoamericano de Teatro de Madrid, con el auspicio del Instituto de Cooperación Iberoamericana. En 1991 obtiene el Premio SGAE, de la Sociedad General de Autores de España, por su obra El dragón de fuego, y el mismo año es finalista del Premio Tirso de Molina (https://es.wikipedia.org/wiki/Roma_ Mahieu) [03/04/2016].

\subsubsection{Juegos a la hora de la siesta}

Juegos a la hora de la siesta fue estrenada en Argentina en 1976, y en España el 30 de abril de 1980, a las 22:30 h., en el Teatro Lavapiés de Madrid, por la compañía Teatro de la Peste, bajo la dirección de Domingo Lo Giudice. Durante el quinquenio objeto de nuestro estudio, este espectáculo se representó 11 veces, todas en 1980.

El drama tiene un único espacio escénico, una plaza con cemento donde juegan los niños. Diego, que tiene siete años, juega a la guerra. Poco a poco se van uniendo los otros niños. Cambian diferentes juegos, y al final simulan un entierro para un gorrión muerto. El juego deriva en una pelea contra Susana, que acaba muriendo. Entonces todos los niños se van a sus casas, asustados.

La autora pide que los personajes de la obra sean interpretados por adultos, en una obra que resulta ser un alegato contra la violencia. Todos los juegos de los niños acaban con la crueldad y la violencia, ya que estos se pegan unos a otros, en una continua lucha por conquistar el poder. También el lenguaje es muy fuerte, con un dominio de las palabrotas y de los insultos. Como afirma Pablo Gorlero en su artículo:

Esa idea sirve para reflejar, a través de la violencia infantil, la opresión sádica y salvaje de la sociedad, desde una visión piramidal, y de los mismos individuos, como comunidad. Pero la obra tiene una trampa. No es una simple mirada sobre el mundo de los niños, sino que ellos son utilizados como un reflejo de los adultos. Es decir, el sadismo de los mayores queda plasmado a través de las distintas aristas de la brutalidad infantil. Lo que hacen estos 
chicos es imitar los comportamientos más salvajes y mezquinos de los grandes (Gorlero, 2006: 1).

La obra volvió a ser representada en 2009 por la compañía Cero Grupo Teatro. En la página web del grupo teatral puede leerse:

Metáfora de la realidad a través de los juegos de unos niños en un parque a la hora de la siesta, a través de los cuales podemos observar el mundo de los adultos, dominado por la violencia, la discriminación y la crueldad. Roma Mahieu declara que es su primera obra y que la escribió en una sola noche. "A pesar de que sus protagonistas -interpretados por adultos- son niños de cinco a ocho años y un retrasado mental adolescente, es decir, que también tiene una edad mental infantil, está concebida pensando en el mundo de los mayores. El universo de los niños se me impuso por sí mismo porque descubrí que solo ellos actúan con la necesaria espontaneidad y franqueza". Superados los treinta años de su estreno, Juegos a la hora de la siesta permanece tan joven y vigente como entonces: la violencia cambia de forma, de cara, pero se recrudece día a día (http://cerogrupoteatro.com.ar/juegos-a-la-hora-de-lasiesta) [04/04/2016].

\subsection{LOURDES ORTIZ}

\subsubsection{Apuntes biográficos}

Lourdes Ortiz es una escritora española que ha cultivado casi todos los géneros, teatro, poesía, ensayo, narrativa y periodismo. Nace en Madrid el 4 de marzo de 1943. Se educa en un colegio de monjas hasta los dieciséis años. A los diecinueve años se casa con el poeta Jesús Munárriz, de quien tiene un hijo. Es licenciada en Geografía e Historia por la Universidad Complutense de Madrid. Trabaja como profesora de Historia y de Sociología del Arte en la UNED y en la Facultad de Periodismo de Madrid. También es miembro del comité de lectura del Centro Dramático Nacional y desde 1976 es catedrática de Teoría e Historia del Arte en la Real Escuela Superior de Arte Dramático de Madrid (RESAD), de la que fue directora desde el año 1991 al 1993. En 1962 ingresa, junto a su marido, en el clandestino PCE, pero lo abandona tras la invasión de Praga por los soviéticos en 1968. El mismo año se divorcia de Jesús Munárriz. Convive después con el filósofo Fernando Savater y en los ochenta con el actor y escritor Daniel Sarasola. Colabora en El País, El Mundo, Diario 16, con columnas 
de opinión sobre temas sociales y políticos, y en otros periódicos y revistas; participa incluso en diversas tertulias de radio y televisión.

Desde los años setenta, se dedica a la literatura. Su obra trata con frecuencia los temas desde el punto de vista del feminismo $y$, aunque muy atenta a la actualidad, recurre con frecuencia a mitos clásicos o a la historia. En 1979 la autora publica Picadura mortal, novela policíaca en la que aparece la primera detective de la literatura española, Bárbara Arenas, que investiga la desaparición de un hombre de negocios en las Islas Canarias. En 1995 es finalista del premio Planeta con su novela La fuente de la vida. (http://www.biografiasyvidas.com/biografia/o/ortiz_lourdes.htm) [03/04/2016].

\subsubsection{Fedra}

Fedra fue escrita en 1983 y estrenada en el Teatro Lope de Vega de Sevilla en 1984. En Madrid, fue representada dos veces en el quinquenio que hemos analizado, el 18 y el 19 de septiembre de 1984, a las 20:30 h., en la Sala San Pol por el Taller de Arte Dramático de Madrid.

La obra es una versión moderna de la homónima obra clásica. En su Fedra, Lourdes Ortiz recrea la tragedia griega y su protagonista, aunque cargándolas de sentidos inéditos, frutos de una nueva época, la de los años ochenta, y de su liberación sexual:

En Fedra Ortiz retoma la leyenda y realiza una revisión de ésta mediante la metaliterariedad y auto-referencialidad a los preceptos del mito [...]. La dramaturga apunta a una nueva imagen de la figura femenina como ejemplo de apertura hacia nuevas posibilidades de relación humanas. La pieza subvierte la trama original y nos propone un desenlace que rompe con la tradición y aboga por una actitud moderada y tolerante hacia la consecución del placer sexual (Ibáñez-Quintana, 2008: 15).

La autora reivindica el cuerpo femenino como sujeto activo de deseo; de aquí nace su Fedra, que se opone al papel que la sociedad le ha conferido, de su obediencia y sumisión al orden patriarcal, para llenarse de deseos de placer y de libertad, y convertir éstos en sus únicos mandamientos.

En toda la obra dramática de la autora subyace el conflicto entre poder y amor. En esta tragicomedia, Lourdes Ortiz desarrolla la idea de que la norma es un mecanismo de control utilizado por los que detentan el poder para seguir poseyéndolos y dominarlos. Sin embargo, esta nueva Fedra no obedecerá a las leyes y seguirá su pasión. Frente al clásico desenlace de Séneca o de Eurípides, la protagonista, al final, no será castigada con 
la muerte, sino premiada con el disfrute alternativo y consentido de los dos lechos, el del padre y el del hijo (Casado Vegas, 2004: 38-39).

\subsection{MARTA SCHINCA}

\subsubsection{Apuntes biográficos}

Marta Schinca, catedrática emérita de Técnica y Expresión del Movimiento en la Real Escuela Superior de Arte Dramático de Madrid (RESAD), es una pionera de la enseñanza y la investigación en el campo de la expresión corporal en España.

Nace el 19 de agosto de 1940 en Montevideo, Uruguay. Bachiller en Medicina, realiza estudios en la Facultad de Humanidades y Ciencias de Montevideo, en Letras y Musicología, así como en Música y Ritmo. En 1969 se traslada con su familia a España, donde realiza una labor investigativa, pedagógica y artística a partir de la cual crea un método propio de Expresión corporal.

La vida de Marta Schinca se caracteriza por una larga experiencia profesional tanto en la actividad artística como en la pedagógica. Desde 1974 hasta 1979 es directora del Departamento de Psicomotricidad en el Centro de Investigación y Orientación Psicológica (CIOS); además de la cátedra en la RESAD, desde 1978 hasta hoy, es vicedirectora de la misma escuela desde el año 1998 hasta el 2000; desde 1992 es también profesora en el Máster en Práctica Psicomotriz de la Facultad de Psicología de la Universidad Complutense.

En el año 1969 funda el Estudio Schinca, centro dedicado a la enseñanza y a la investigación del arte de movimiento, que ella misma dirige hasta 1990. Es asimismo la fundadora de una compañía teatral, la Compañía Schinca Teatro de Movimiento, que se ha centrado siempre en las posibilidades expresivas del movimiento del actor. Con Yegua de la noche (Real Coliseo Carlos III de El Escorial, 2001), producida por Zascandil Teatro e interpretado en solitario por Helena Ferrari, en el año 2002 ha obtenido el segundo premio a la mejor Dirección en el V Certamen para Directoras de escena (http://estudioschinca. com/Marta-Schinca.html) [04/04/2016].

\subsubsection{Concierto en diagonal}

Estrenada en la Sala Cadarso de Madrid en 1979, este espectáculo volvió a representarse el 20 de noviembre de 1980 en el mismo teatro en 18 ocasiones. Bajo la dirección de Marta Schinca, actuaron Brigitte Aschwanden, Helena Ferrari, Pedro Garhel y Roger Álvarez. Dadas sus características peculiares, este espectáculo pertenece al género del teatro del gesto. 
En una entrevista de Ángel Laborda, la autora explica que la base de su espectáculo es el ritmo:

\section{[...] Creemos que toda la Naturaleza es movimiento y que ese movimiento es} ordenado; es decir, un ritmo. El cuerpo humano es puro ritmo: atendemos a su desarrollo y la belleza de su organización. No crea por ello que se detiene en lo puramente natural; el ritmo es humanístico, es un misterio (Laborda, 1980: 55).

En un extracto del programa del espectáculo, leemos:

Los diferentes signos corporales o sonoros que se generan en escena no responden a una coreografía preconcebida, sino que surgen de una improvisación colectiva que responde al devenir de los estímulos, creando cada vez una expresión irrepetible, única. Es decir, que existen en cada número unas pautas previstas, unas premisas de trabajo muy claras, unos puntos a los que se debe llegar indefectiblemente: pero el camino para hacerlo es siempre distinto, creándose, desarrollándose cada vez en forma diferente en la propia escena (Hormigón, 2003: 754).

La recepción crítica de la obra, reconociendo la peculiaridad del espectáculo propuesto por Marta Schinca, fue positiva. Lorenzo López Sancho, en las páginas de ABC de Madrid, afirma:

[...] Frecuentemente, los actores no consiguen alcanzar lo que podríamos denominar un estado de pureza significativa. El esfuerzo de Marta Schinca y sus colaboradores por obtener esa forma de libertad expresiva alcanza cotas estimables, naturalmente, para quienes tengan un interés previo por este tipo de descubrimientos (López Sancho, 1980b: 61).

De hecho, el mismo Ángel Laborda, al final de la entrevista sobredicha, subraya la peculiaridad yel carácter sectorial de Conciertoen diagonal, definiéndolo“[...] un espectáculo insólito, que interesa mucho, de antemano, a todos los estudiosos del fenómeno teatral en todas sus manifestaciones" (Laborda, 1980: 55). 


\section{CONCLUSIONES}

En este artículo hemos analizado, tras previa selección, las puestas en escena de siete dramaturgas españolas o afincadas en España: Antonia Bueno Mingallón, Ana Diosdado, Isabel Hidalgo Muñoz, María Teresa León, Roma Mahieu, Lourdes Ortiz, Marta Schinca.

Aunque el panorama cultural y social en aquellos años empieza a mejorar, aún en los primeros años ochenta el cambio no es completo. Va modificándose, abriéndose a las nuevas corrientes $y$, sobre todo, al mundo femenino, pero todavía las autoras y dramaturgas son muy pocas. El espacio teatral, como ya hemos dicho, es el último que las mujeres logran conquistar en el ámbito artístico. De hecho, en el quinquenio 1980-1984, de un total de 448 autores catalogados (Bonaccorsi, 2015: 1181), solo 28 eran dramaturgas, frente a 419 hombres, con un porcentaje que llega apenas al $6,25 \%$ con respecto al total de los autores.

Dados los condicionantes de espacios que exige un artículo como este, hemos analizado la vida y la obra de siete dramaturgas. La elección no ha sido casual. Cada una ha sido seleccionada por un motivo distinto, porque cada una representa un aspecto diferente dentro del grupo de las autoras de los años ochenta. Antonia Bueno Mingallón, además de ser dramaturga, directora y actriz, creó la compañía teatral Teatro Guirigai, y coodirigió su gestión artística durante más de veinte años. Ana Diosdado fue una de las dramaturgas más conocidas y de mayor éxito en los años ochenta. Cuando en 1984 Patricia W. O'Connor dedicó monográficamente a las dramaturgas españolas el número de otoño de la revista Estreno, todas las creadoras que allí aparecen, con excepción de Ana Diosdado, expresaron la dificultad de acceder al espacio público del teatro, porque tal espacio pertenecía por costumbre a los hombres, así como la dificultad, en igualdad de condiciones con los dramaturgos, de conquistar un lugar para estrenar sus obras.

María Teresa León nació en un ambiente culto. Su tía María, esposa de Ramón Menéndez Pidal, había sido una de las primeras mujeres en lograr en España un doctorado en Filosofía y Letras y en impartir clases en la Universidad española. No obstante, María Teresa padeció y sufrió su condición de mujer, aún en los años ochenta. Al dejar a su marido por el escritor Rafael Alberti, tuvo que separarse de sus dos hijos, dado que por entonces la custodia recaía indefectiblemente en el esposo. Fue, no obstante, una mujer muy activa, viajó mucho, y se compromitió política y socialmente durante los años de la Guerra Civil Española. Siendo Subdirectora del Consejo Central del Teatro, puso en marcha diversas empresas teatrales, trabajando como dramaturga, como directora de escena e incluso esporádicamente como actriz: fue co-directora de Los Títeres de cachiporra, de Federico García Lorca y de La cacatúa verde, de Arthur Schnitzler; dirigió La tragedia optimista, del autor ruso Vsevolod Vichnievsky y realizó, dirigió y participó como actriz en la versión de Numancia, de la que se encargó el propio Alberti. Igualmente dirigió y participó en la obra 
de Alberti Cantata de los héroes y la fraternidad de los pueblos. Otra de sus aportaciones al mundo del teatro fue su participación en la fundación de "El Cine, Teatro, Club de la Alianza de Intelectuales Antifascistas".

Isabel Hidalgo Muñoz es un ejemplo de la poca atención que han recibido las dramaturgas españolas en los años ochenta por sus contemporáneos, por la crítica y por los estudios sobre lo teatral en general. Las escasas informaciones que ofrecemos sobre su vida y sus obras, de hecho, se deben a este aspecto, dado que solo en Autoras en la historia del teatro español (1500-2000), dirigido por Juan Antonio Hormigón, ha sido posible encontrar algunas noticias sobre esta autora.

Roma Mahieu y Lourdes Ortiz constituyen, cada una a su manera, dos ejemplos de autoras y artistas polifacéticas. Ambas cultivaron la pasión de la escritura dedicándose a géneros literarios muy diferentes entre ellos, como guiones televisivos (Historia de amor y de muerte), piezas radiofónicas, cuentos y novelas (Diario íntimo de Odolinda Correa, Sagrario y Lo que me molesta es salir a la calle y juntar sus pedazos). Como Roma Mahieu, Lourdes Ortiz cultivó el periodismo -colaboró en El País, El Mundoy Diario 16, con columnas de opinión sobre temas sociales y políticos, participó incluso en diversas tertulias de radio y televisión; asimismo colaboró en el programa Así es la vida dirigido por Nieves Herrero en Radio Nacional de España y en La Mirada Crítica, coloquio-tertulia que acompañaba a los informativos de la mañana en la cadena de televisión Telecinco- y la narrativa, llegando a ser finalista del Premio Planeta en 1995 con su novela La fuente de la vida.

Por último, Marta Schinca es la representante de un teatro diferente, un teatro que mezcla los aspectos más propiamente teatrales con otros que pertenecen a géneros muy diferentes, como la danza, la música y lo gestual. Es un ejemplo de búsqueda de nuevas fronteras en lo teatral, de la experimentación y de la armonización de elementos distintos en una única obra. Además, Marta Schinca fundó el Estudio Schinca, centro dedicado a la enseñanza y a la investigación del arte de movimiento, y la Compañía Schinca Teatro de Movimiento, en una incesante indagación de las posibilidades expresivas del movimiento del actor.

En el presente artículo, hemos analizado una obra por cada una de las siete autoras tratadas. La elección ha sido intencionada, porque se han examinado los espectáculos que se estrenaron en el quinquenio 1980-1984, en la capital de España, según el periódico elegido. Ninguna dramaturga tuvo la suerte de ver representado en aquellos cinco años más de un espectáculo. Sin embargo, este es el único aspecto que une los siete espectáculos hasta aquí descritos. Si analizamos el número de funciones, de hecho, nos damos cuenta inmediatamente de la enorme diferencia que hay entre una obra y otra. Como podemos averiguar en la tabla siguiente: 


\begin{tabular}{l|l|l}
\hline Espectáculo & Autora & Número de funciones \\
\hline Las desempleadas & Isabel Hidalgo & 171 \\
Concierto en diagonal & Marta Schinca & 18 \\
Ágape & Antonia Bueno & 14 \\
Juegos a la hora de la siesta & Roma Mahieu & 11 \\
Juan bobo & María Teresa León & 7 \\
Olvida los tambores & Ana Diosdado & 2 \\
Fedra & Lourdes Ortiz & 2 \\
\hline
\end{tabular}

Tabla 1.1

Como se puede constatar, los espectáculos han sido ordenados por el número de funciones, en orden decreciente. La obra más representada, entre las siete analizadas, fue Las desempleadas, la única que alcanza, y sobrepasa las cien funciones. Todas las restantes fueron escenificadas entre 18 y 2 veces, esto es, muy poco en una ciudad como Madrid. Naturalmente, un número tan bajo de funciones refleja un escaso interés hacia aquellas obras, y/o un limitado, si no totalmente ausente, éxito de público y de crítica.

Lógicamente, el análisis de apenas siete obras teatrales no puede ser suficiente como para analizar las tendencias del teatro de los años ochenta, ni desde el punto de vista femenino, ni desde una perspectiva más general. Para una mejor comprensión de la cartelera teatral madrileña en los años 1980-1984, es necesario volver a nuestra tesis doctoral y a su cartelera teatral, reconstruida, lo recordamos, a través de una única fuente documental, el $A B C$ de Madrid, y de su hemeroteca digital, disponible en línea (http:// hemeroteca.abc.es).

A continuación, constatamos las autoras incluidas en la cartelera citada. Al lado de cada una de ellas, hemos señalado el número de funciones. Cabe señalar, aunque por problemas de espacio no podemos examinar, que solo la autora italiana Franca Rame representó tres obras en los años 1980-1984, y que Sara Montiel representó dos obras diferentes. De las restantes 26 solo se escenificó un solo un espectáculo.

\begin{tabular}{l|l}
\hline Autora & Número de funciones \\
\hline Huercas, Isabel & 279 \\
Díaz, Marujita (Díaz Ruiz, María del Dulce Nombre) - Actriz & 176 \\
Hidalgo, Isabel & 171 \\
Norman, Marsha & 153 \\
Abril, Dolores & 146 \\
Darbon, Leslie & 129 \\
Montiel, Sara - Actriz & 124 \\
Rame, Franca & 110 \\
Swados, Elisabeth & 90 \\
Moreno, Antoñita - Actriz & 71 \\
Maraini, Dacia & 47
\end{tabular}




\begin{tabular}{l|l}
\hline Autora & Número de funciones \\
\hline Gems, Pam & 38 \\
Chaplin, Victoria & 20 \\
Schinca, Marta & 18 \\
Fuertes, Gloria & 17 \\
Aragón, Rita Irasema & 16 \\
Bueno Mingallón, Antonia & 14 \\
Mahieu, Roma & 11 \\
Cardone, Adriana & 7 \\
Hermida, Alicia & 7 \\
León Goyri, María Teresa & 7 \\
Ballesteros, María Paz & 6 \\
León Rodríguez, María Dolores & 6 \\
Ribas, Isabel & 6 \\
Diosdado, Ana & 2 \\
Machado, Maria Clara & 2 \\
Ortiz, Lourdes & 2 \\
Muñoz Sampedro, Mercedes & 1 \\
\hline
\end{tabular}

Tabla 1.2

La dramaturga que encabeza la lista es Isabel Huercas, que representó solo una obra en aquellos años, pero de amplio éxito: la comedia Rematadamente locos. El espectáculo fue representado en el Teatro Alfil durante el 1980, y volvió a representarse dos años más tarde, en el 1982, esta vez en el Reina Victoria. Tras examinar la Tabla 1.2, nos damos cuenta fácilmente de que muy pocas son las dramaturgas que tuvieron éxito en los años ochenta. Más de la mitad, 16 en total, no superaron las veinte funciones. Sin embargo, hay que tener en cuenta que las 28 autoras que hemos constatado en nuestra tesis de doctorado deberían considerarse un tanto afortunadas, porque, como hemos visto, aún en los años ochenta muy raramente una mujer lograba representar una obra en los teatros españoles. Recordamos, a este propósito, que el número de las autoras constituye un poco más del $6 \%$ del total de los autores presentes en los escenarios madrileños de aquellos años. Como ya habíamos afirmado, de hecho, los años ochenta no constituyen aún el lugar ideal para las autoras españolas. La década de los noventa representará finalmente un período de mayor igualdad, en el que las dramaturgas compartieron con los otros autores dramáticos los mismos problemas, sin aquella sensación castrante de la que se hablaba en la revista Estreno algunos años antes.

Gracias a las dramaturgas, el teatro goza de importantes aportaciones, de un nuevo enriquecimiento en los temas y en el lenguaje. Como afirma Virtudes Serrano:

Esta incorporación [...] de las mujeres al teatro ha favorecido una nueva y enriquecedora visión del mundo que se proyecta sobre la escena. Es una 
mirada distinta que [...] percibe la realidad con unos matices que no son los habituales para el canon establecido (Serrano, 2005: 96).

Una nueva mirada, entonces, que se carga de experiencias y puntos de vistas diferentes, y que enriquece el mundo teatral abriendo el paso a nuevos caminos y a nuevas búsquedas.

\section{REFERENCIAS BIBLIOGRÁFICAS}

BONACCORSI, Annalisa Domenica (2015). Cartelera teatral en "ABC" de Madrid (1980-1984). Tesis de doctorado, dirigida por José Romera Castillo. Inédita hasta el momento en formato impreso, aunque puede leerse en la web del Centro: http://www2.uned.es/ centro-investigacion-SELITEN@T/pdf/Tesis_Cartelera_teatral_ABC_Madrid_1980-1984.pdf [03/03/2016].

CASADO VEGAS, Alicia (2004). "La destrucción o el amor. La obra dramática de Lourdes Ortiz". Acotaciones: Revista de Investigación Teatral 12, 33-44 (también en http://www.resad.es/ acotaciones/acotaciones 12/12casado.pdf) [06/05/2016].

CONDE, Víctor (2007). “Olvida los tambores". Internet Archive, agosto. Disponible en http://web. archive.org/web/20090607015906/http:/www.victorconde.com/tambores.html [03/03/2016]. DIOSDADO, Ana (1988). (2007). Olvida los tambores. Madrid: Asociación de Directores de Escena.

FLOECK, Wilfred et alii (eds.) (2008). Dramaturgias femeninas en el teatro español contemporáneo: entre pasado y presente. Hildesheim (Alemania): Olms.

GARCÍA-PASCUAL, Raquel (coord.) (2012). "Sobre lo grotesco en autoras teatrales de los siglos XX y XXI". Signa. Revista de la Asociación Española de Semiótica 21, 11-197 (también en http://bib.cervantesvirtual.com/servlet/SirveObras/06925171155959240910046/index.htm) [03/04/2016].

GORLERO, Pablo (2006). “Una parábola del miedo y la violencia”. La Nación, 8 de octubre (también en http://www.lanacion.com.ar/847514-una-parabola-del-miedo-y-la-violencia) [03/03/2016]).

HIDALGO MUÑOZ, Isabel (1990). Todas hijas de su madre. Madrid: Machado Grupo Distribución. HORMIGÓN BLÁZQUEZ, Juan Antonio (ed.) (2000). Autoras en la historia del teatro español (1500-2000). Madrid: Publicaciones de la ADE.

(2003). Directoras en la historia del teatro español (1550-2002). Madrid: Publicaciones de la ADE.

IBÁÑEZ-QUINTANA, Nuria (2008). Visiones convergentes: Mito, historia y arquetipo en la dramaturgia de Lourdes Ortiz, Sabina Berman y Diana Raznovich. Kalamazoo, Michigan: Western Michigan University. 
LABORDA, Ángel (1980). "Concierto en diagonal, en la Sala Cadarso". ABC de Madrid, 20 de noviembre, 55 (también en http://hemeroteca.abc.es/nav/Navigate.exe/hemeroteca/ madrid/abc/1980/11/20/067.html) [03/03/2016].

LEÓN, María Teresa (2009). Rosa-Fría, patinadora de la luna. Madrid: Ediciones de la Torre.

LÓPEZ SANCHO, Lorenzo (1980a). “Las desempleadas, o no es tan fácil el vodevil". ABC de Madrid,

21 de agosto, 39 (también en http://hemeroteca.abc.es/nav/Navigate.exe/hemeroteca/ madrid/abc/1980/08/21/047.html) [03/03/2016].

(1980b). "Concierto en diagonal, experimento predramático". ABC de Madrid, 4 de diciembre, 61 (también en http://hemeroteca.abc.es/nav/Navigate.exe/hemeroteca/madrid/ abc/1980/12/04/073.html) [03/03/2016].

LO PORTO, Valeria (2012). “Puestas en escena de obras de dramaturgas en la cartelera de $A B C$ de Madrid (1990)". Signa. Revista de la Asociación Española de Semiótica 21, 369-393 (también en http://www.cervantesvirtual.com/obra/puestas-en-escena-de-obras-de-dramaturgas-enla-cartelera-de-abc-de-madrid-1990/[05/04/2016].

(2013). Cartelera teatral en "ABC" de Madrid (1990-1994). Tesis de doctorado, dirigida por José Romera Castillo. Inédita, aunque puede leerse en http://www.uned.es/centroinvestigacion-SELITEN@T/pdf/ValeriaLoPorto.pdf [05/04/2016].

O'CONNOR, Patricia (1988). Dramaturgas españolas de hoy. Una introducción. Madrid: Editorial Fundamentos.

ORTIZ, Lourdes (2013). Fedra. Madrid: Ediciones Irreverentes (disponible también en línea: http://www.noticiasirreverentes.com/inicio_libros/FEDRA.pdf) [04/04/2016].

PÉREZ, Miguel Ángel -Manolo- (2007). “'Los del Teloncillo'. Una peripecia personal”. Teatro Teloncillo, en http://www.cylcultural.org/teatro/teloncillo [04/04/2016].

PIÑEIRO BARDERAS, Sonia (2012). Estudio de las dramaturgas españolas (siglos XX y XXI) en el Centro de Investigación de Semiótica Literaria, Teatral y Nuevas Tecnologías de la UNED. Trabajo de investigación defendido en la UNED, en noviembre de 2012, bajo la dirección del Dr. José Romera Castillo. Inédito hasta el momento en formato impreso, aunque puede leerse en la web del Centro:http://www2.uned.es/centro-investigacion-SELITEN@T/pdf/tfm/ Sonia_Pineiro.pdf [04/04/2016].

ROMERA CASTILLO, José (2010). “Estudio de las dramaturgas en los Seminarios Internacionales del SELITEN@T y en la revista Signa. Una guía bibliográfica". En Teatrología. Nuevas perspectivas. Homenaje a Juan Antonio Hormigón, M. F. Vieites y C. Rodríguez (eds.), 338357. Ciudad Real: Ñaque.

(2011). "Las dramaturgas y el SELITEN@T". En su obra, Pautas para la investigación del teatro español y sus puestas en escena, 381-411. Madrid: UNED (puede leerse en http:// www2.uned.es/centro-investigacion-SELITEN@T/pdf/EstudiosTeatro/7Dramaturgas_siglosXXXXI.pdf) [03/04/2016]. 
(2014). "Algo más sobre dramaturgias femeninas en los inicios del siglo XXI". En Del gran teatro del mundo al mundo del teatro. Homenaje a la profesora Urszula Aszyk, Karolina Kumor y Katarzyna Moszczynska-Dürst (eds.), 245-255. Varsovia: Instituto de Estudios Ibéricos e Hispanoamericanos de la Universidad de Varsovia.

ROMERA CASTILLO, José (ed.) (2003). Teatro y memoria en la segunda mitad del siglo XX. Madrid: Visor Libros.

(2005). Dramaturgias femeninas en la segunda mitad del siglo XX: espacio y tiempo. Madrid: Visor Libros. (2006). Tendencias escénicas al inicio del siglo XXI. Madrid: Visor Libros. (2012). "Sobre teatro breve de hoy y obras de dramaturgas en la cartelera madrileña (1990 y 2000)". Signa. Revista de la Asociación Española de Semiótica 21, 199-415(también en http://bib.cervantesvirtual.com/servlet/SirveObras/06925171155959240910046/index.htm) [03/04/2016].

ROSWITA / GARNIER, Emmanuelle (eds.) (2007). Transgression et folie dans les dramaturgies féminines hispaniques contemporaines. Carnières-Morlanwelz (Bélgica): Lansman Éditeur. SERRANO, Virtudes (2005). "El espacio y el tiempo de la mujer en la dramaturgia femenina finisecular". En Dramaturgias femeninas en la segunda mitad del siglo XX: espacio y tiempo, José Romera Castillo (ed.), 95-108. Madrid: Visor Libros.

HARO, Eduardo (1983). "Un festín sucio". El País, 6 de febrero (en http://elpais.com/ diario/1983/02/06/cultura/413334013_850215.html) [04/04/2016].

TORRES NEBRERA, Gregorio (1984). “La obra literaria de María Teresa León (cuentos y teatro)". Anuario de Estudios Filológicos 7, 361-384.

VIOLA, Anita (2012a). Cartelera teatral en "ABC" de Madrid (2000-2004). Tesis de doctorado, dirigida por José Romera Castillo. Inédita hasta el momento en formato impreso, aunque puede leerse en la web del Centro: http://www.uned.es/centro-investigacion-SELITEN@T/ pdf/AnitaViola.pdf [04/04/2016].

(2012b). "Puestas en escena de obras de dramaturgas en la cartelera de $A B C$ de Madrid (2000)". Signa. Revista de la Asociación Española de Semiótica 21, 395-415 (también en http:// descargas.cervantesvirtual.com/servlet/SirveObras/04702707659336506317857/047380. pdf?incr=1) [04/04/2016].

Recibido el 30 de mayo de 2016.

Aceptado el 18 de noviembre de 2016. 